\title{
Recomendações de Design para Interfaces de Jogos Acessíveis para Crianças Disléxicas
}

\author{
Renato Eubank de Almeida \\ Instituto Federal de Mato Grosso do Sul \\ Ponta Porã - MS, Brasil \\ renatoeubank3@gmail.com \\ Kenia de Souza Oliveira \\ Instituto Federal de Mato Grosso do Sul \\ Ponta Porã - MS, Brasil \\ kenia.oliveira@ifms.edu.br
}

\author{
Rodrigo Gabriel Galeano da Silva \\ Instituto Federal de Mato Grosso do Sul \\ Ponta Porã - MS, Brasil \\ rodrigogabriel34@gmail.com \\ Esteic Janaina Santos Batista \\ Instituto Federal de Mato Grosso do Sul \\ Ponta Porã - MS, Brasil \\ esteic.batista@ifms.edu.br
}

\section{RESUMO}

Este trabalho é uma proposta de recomendações de design de interfaces de jogos educacionais acessíveis às crianças diagnosticadas com dislexia. Para as definições destas recomendações, nos baseamos em estudos de Interação CriançaComputador, elementos de jogos e estudos sobre abordagens pedagógicas com crianças disléxicas. A motivação deste trabalho deve-se ao fato de a dislexia ser um assunto relevante, devendo ser abordado nas mais diversas áreas do conhecimento, uma vez que poucos jogos e aplicações estão disponíveis para estimular o processo de ensino-aprendizagem desse público.

\section{KEYWORDS}

guidelines, dislexia, games, interface

\section{INTRODUÇÃO}

Apesar de a dislexia ser algo presente nos dias atuais e segundo dados levantados por [6], estimou-se que aproximadamente $15 \%$ da população mundial é portadora de dislexia, significando uma média de quatro a cinco sujeitos em cada classe de trinta alunos, sendo poucas as ferramentas disponíveis para auxiliar no desenvolvimento de crianças disléxicas.

Diante do exposto, o objetivo deste projeto é propor recomendações para o desenvolvimento de interfaces de jogos

Permission to reproduce or distribute, in whole or in part, material extracted from this work, verbatim, adapted or remixed, as well as the creation or production from the content of such work, is granted without fee for noncommercial use, provided that the original work is properly credited. IHC 2019 - TRILHA PÔSTERES E DEMONSTRAÇÕES, Outubro 21 - 25, 2019, Vitória, Brasil. In Anais Estendidos do XVIII Simpósio Brasileiro sobre Fatores Humanos em Sistemas Computacionais. Porto Alegre: SBC. Âl' 2019 by the author(s), in accordance with the terms of the Creative Commons Attribution-NonCommercial 4.0 International Public License (CC BY-NC $4.0)$.

IHC'19, Octuber 21-27, 2019, Vitoria, ES

(c) 2019 destinados ao público de crianças disléxicas, com intuito que estas atinjam seus objetivos educacionais.

Seguir recomendações no desenvolvimento de uma interface facilita para que a ferramenta atinja as metas de usabilidade. Usabilidade é um dos objetivos da Interação HumanoComputador (IHC), área que segundo [5], preocupa-se com a facilidade de uso de um produto, sendo metodologias e ferramentas voltadas ao desenvolvimento de interfaces.

Para a validação destas recomendações, elas estão sendo aplicadas em um jogo web e móvel que será voltado para os graus leve e médio de dificuldade da dislexia, uma vez que sua ênfase é na habilidade de escrita e leitura. Ambos os graus mencionados são marcados por erros na escrita como inversões, substituições e omissões de letras.

\section{ESTADO DA ARTE}

\section{Interação Criança-Computador}

Este trabalho baseou-se em estudos da área de Interação Criança-Computador, uma subárea de IHC, que diz respeito ao estudo da concepção, avaliação e implementação de sistemas computacionais interativos para crianças.

O principal que nos baseamos foi de [1], apresenta diretrizes de Interação Criança-Computador (ICC) para a criação de interfaces para o público infantil a partir de um extenso estudo bibliográfico em IHC, ICC, psicologia na educação a partir de análise de interfaces destinadas ao público infantil. As principais recomendações, foram separadas em categorias como: uso de affordances, feedback, navegação, gestos, sons, cores, tipografia, personagens, colaboração e participação dos pais.

\section{Práticas Pedagógicas para Interação com Alunos Disléxicos}

A dislexia muitas vezes só é notada na escola, de acordo com a [4], sendo um ambiente onde o aluno tem contato com a escrita e a leitura, porém muitos professores não têm no seu currículo de formação inicial e/ou estão preparados para 
trabalhar ou identificar estas dificuldades do aluno, o que pode resultar em frustração e abandono escolar por parte do alunol. Os autores [3] e [2] citam atitudes e comportamentos para facilitar a interação com alunos diagnosticados com dislexia, sendo algumas delas:

- Resumir conteúdos e valorizar acertos;

- Dar "dicas" e orientar o aluno de como se organizar e realizar as atividades;

- Não insistir em exercícios de fixação repetitivos e numerosos, pois isto não diminui a dificuldade do aluno e pode aumentar a frustração dele.

- Dar ao aluno tempo suficiente para responder as questões;

- Usar uma linguagem direta, clara e objetiva na hora da explicação;

- Sublinhar palavras-chave e frases mais relevantes;

\section{METODOLOGIA}

Este trabalho está dividido em 4 etapas. Na primeira, foram realizadas pesquisas bibliográficas em relação aos seguintes temas: a) habilidades e dificuldades de crianças com dislexia, b) abordagens pedagógicas para interagir com alunos disléxicos, c) interação humano-computador, d) interação criança-computador.

$\mathrm{Na}$ segunda e atual etapa foram definidas as recomendações para o desenvolvimento de interfaces de jogos para crianças diagnosticadas com dislexia que serão validadas e avaliadas por profissionais da Educação Especial e fonoaudiólogos após sua aprovação no Comitê de Ética, por meio de uso na sala de aula e em consultas com estas crianças.

A terceira etapa é destinada à aplicação das recomendações definidas no desenvolvimento de um jogo, que tem como objetivo propor desafios relacionados com a escrita e leitura com intuito de auxiliar no aprendizado de crianças disléxicas.

$\mathrm{Na}$ última etapa o jogo será avaliado com o público final junto com um centro de atendimento à crianças com necessidades especiais e fonoaudiólogos.

\section{RECOMENDAÇÕES PARA O DESENVOLVIMENTO DE INTERFACES}

Levando em consideração estudos de ICC (Interação CriançaComputador), abordagens pedagógicas para interagir com alunos disléxicos e jogos na educação, chegamos a uma lista de recomendações para o desenvolvimento de interfaces para crianças diagnosticadas com dislexia (grau leve e médio) na faixa etária de 6 a 8 anos, algumas delas são:

- Linguagem clara e objetiva: tendo em vista que a criança disléxica tem uma grande dificuldade na leitura, o uso de textos longos e complicados pode acabar prejudicando sua experiência com o jogo e acabar frustrando-as.
- Áudios explicativos: além de ter dificuldade na leitura, crianças preferem escutar do que ler pelo fato de ser menos trabalhoso. Diante disso, o jogo deve conter áudios explicando o seu funcionamento através de um narrador-personagem ou um narrador-observador, que fará o papel de um guia no jogo, desenvolvendo um sentimento de amizade.

- Valorização de acertos e erros: para que a criança não se sinta desmotivada, deve-se valorizar os acertos e aproveitar os erros para dar dicas.

- Evitar o uso excessivo exercícios de fixação repetitivos e cansativos, desta forma, o jogo deve contemplar fases com desafios diversificados.

- Fornecer o feedback ao aluno sobre seu desempenho, dando preferência aos feedbacks auditivos durante o jogo, uma vez que crianças disléxicas possuem mais facilidade com as instruções orais.

- Destinar-se ao desenvolvimento de habilidades voltadas para as maiores dificuldades enfrentadas por um disléxico, através de atividades lúdicas e de caráter educacional.

\section{CONSIDERAÇÕES FINAIS}

O presente trabalho apresentou recomendações para o desenvolvimento de interfaces de jogos para crianças disléxicas, por meio de uma extensa pesquisa bibliográfica na área de ICC, jogos educativos e dislexia. As recomendações serão avaliadas por profissionais da área da educação e saúde, validadas por meio de um jogo.

Espera-se que esta pesquisa possa auxiliar desenvolvedores no design de interfaces de jogos, para que estas sejam acessíveis às crianças diagnosticadas com dislexia.

\section{REFERÊNCIAS}

[1] Esteic Janaina Santos Batista. 2017. Uma Análise de Ambientes de Programação em Blocos com Base em Recomendações de Interação Criança-Computador. Universidade Federal de Mato Grosso do Sul, 1-106. http://br-ie.org/pub/index.php/wie/article/view/7302/5100

[2] Ana Luiza Borba. 2016. Como interagir com o disléxico em sala de aula. Associação Brasileira de Dislexia. http://www.dislexia.org.br/comointeragir-com-o-dislexico-em-sala-de-aula/

[3] Raquel Grilo Oliveira Fernandes. 2016. Escola inclusiva: perceções de professores sobre dislexia, inclusão e estratégias pedagógicas. Ph.D. Dissertation. Instituto Politécnico de Viseu, Escola Superior de Educação de Viseu.

[4] International Dyslexia Association IDA. 2002. Uma Análise de Ambientes de Programação em Blocos com Base em Recomendações de Interação Criança-Computador. International Dyslexia Association. https://dyslexiaida.org/definition-of-dyslexia/

[5] Patrick W Jordan. 1998. An introduction to usability. CRC Press.

[6] Giselle Massi. 2007. A dislexia em questão. Plexus Editora, Brasil. 